\title{
Model and simulation on a shock test bed for gun breechblock system
}

\author{
Yanfeng Yang ${ }^{1}$, Jian Zheng ${ }^{1}$, Changchun $\mathrm{Di}^{1}$, Jingwen Chen ${ }^{2}$ \\ 1. Mechanical Engineering College, Shijiazhuang, 050003, China \\ 2. Office in 152 Factory, Chongqing 401120, China
}

Keywords: dynamics; shock test bed; model; simulation.

\begin{abstract}
In order to test the dynamic characteristics of the shock test bed for gun breechblock system expediently, the dynamic model was established based on the virtual prototype technology. The three-dimensional solid model of each part was established and assembled by software Pro/Engineer. Then the whole model was imported into the dynamic software MSC.ADAMS through the interface, Mechanism/Pro, between the two software. Then the constraints, contacts or spring force between each two parts were added in the model according to the relation in practice. The force outside was imposed on the bearing part. After that, the virtual prototype model was established. With the model, simulation was processed and the dynamic characteristics of the parts of the shock test bed were tested under different conditions. The test results show that the model is tallies with the physical prototype and can be used to analyze the dynamic characteristics of the shock test bed parts.
\end{abstract}

\section{Introduction}

The breechblock system is a mechanical system that is used to fire shell and draw out cartridge case. It is composed of gun breech, breechblock, breechblock operating mechanism and other parts installed on the first two parts. It is shown in Fig. 1. The process of opening breechblock is the main action of the system. That is the breechblock moving down along the inside surface of gun breech. During the process, a spring is pressed and stores up energies of closing breechblock. And the other parts use the motion to complete their own design actions. Being opened, the breechblock falls to the lowest position.

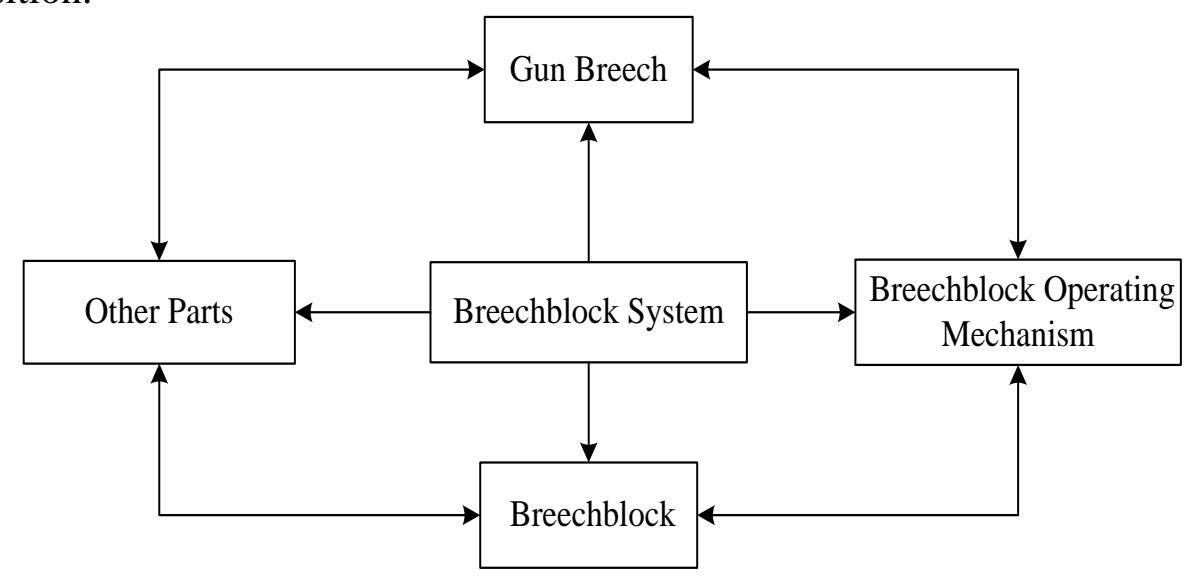

Fig. 1 Breechblock system composition

However, for a long time, more researches on breechblock system were about theories[1,2], methods[3,4] and technologies[5,6], but fewer researches were about tests. For it is hard to develop tests during the firing. As a result, to ensure the tests requirement, a shock test bed for the breechblock system is designed. In order to ensure the safety of test based on the physical prototype, Virtual Prototyping (VP) technology is used to establish the model of shock test bed in this paper, so as to analyze the dynamic characteristics of parts. 


\section{The three-dimensional solid model of shock test bed}

The three-dimensional solid modeling is the first step of virtual prototype establishment. It is also the basis. For the shape of parts in the breechblock system are complex, it is arduous to complete the solid model establishment by the multi-body dynamics software MSC.ADAMS. As a result, we establish the model of each part and assemble the parts in CAD/CAE/CAM software Pro/Engineering which can realize the parametric design and feature modeling.

The models of parts were established according to X-Y scheme. During the modeling, there were punching, chamfering, cutting and so on. The process was just like producing the part. The shock test bed was composed of more than 70 parts. Some parts are shown in Fig. 2.

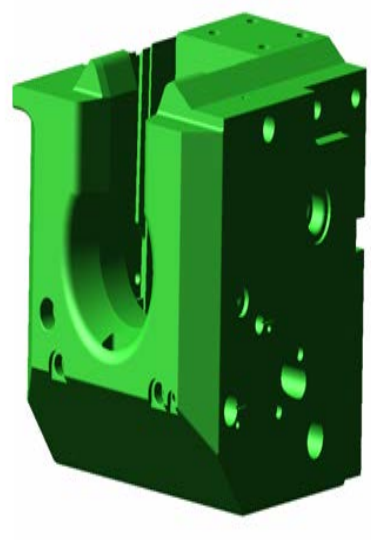

(a) Gun breech

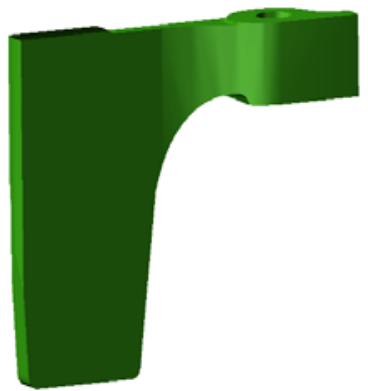

(b) Breechblock operating cam

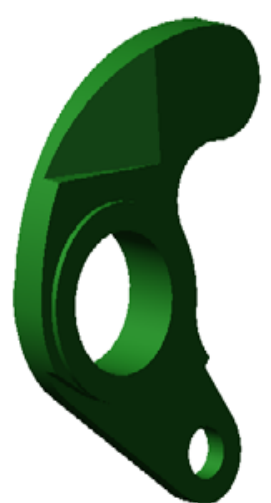

(c) Crank lever

Fig. 2 The three-dimensional solid model of some parts

After the modeling of parts, we need to fit the parts together according to the physical prototype. Some parts were used two or more times and installed different places, such as nut bolt, carrier ring and so on.

\section{The virtual prototype of the system}

After the three-dimensional solid model establishment, the whole model was imported into the dynamic software MSC.ADAMS through the interface, Mechanism/Pro, between the two software. Then the constraints between each two parts were added in the model according to the relation in practice. The constraints included translational, revolute, and fixed. For example, the gun breech is fixed on the ground without motion. The breechblock operating case was translational with the ground. The crank lever is revolute with the gun breech. In addition, contacts or spring force were added between the parts, such as the relation between crank lever and breechblock operating cam.

The contact model is

$F=K_{H} \delta^{e}+C(\delta) \delta$

$F$-normal contact force,

$K_{H}$ - Herts contact stiffness,

$\delta$ - contact point depth of penetration,

$C$-damping divisor, which is the function of $\delta$,

$e$-exponential greater than or equal to 1 .

The spring model is

$F=-K\left(l-l_{0}\right)-\mu \frac{d l}{d t}+F_{0}$ 
$F, F_{0}$ —present and generalized spring force,

$K$ - generalized spring stiffness,

$l, l_{0}$ — present and generalized length of spring,

$\mu$-generalized spring coefficient of damping.

In the model, a force was defined on the breechblock operating case. Then the breechblock operating cam fixed on the case could move along the opposite direction of gun breech to impact crank lever under the force. The motion is shown as an arrowhead in Fig. 3. At last, the virtual prototype model of the shock test bed was established and shown in Fig. 3.

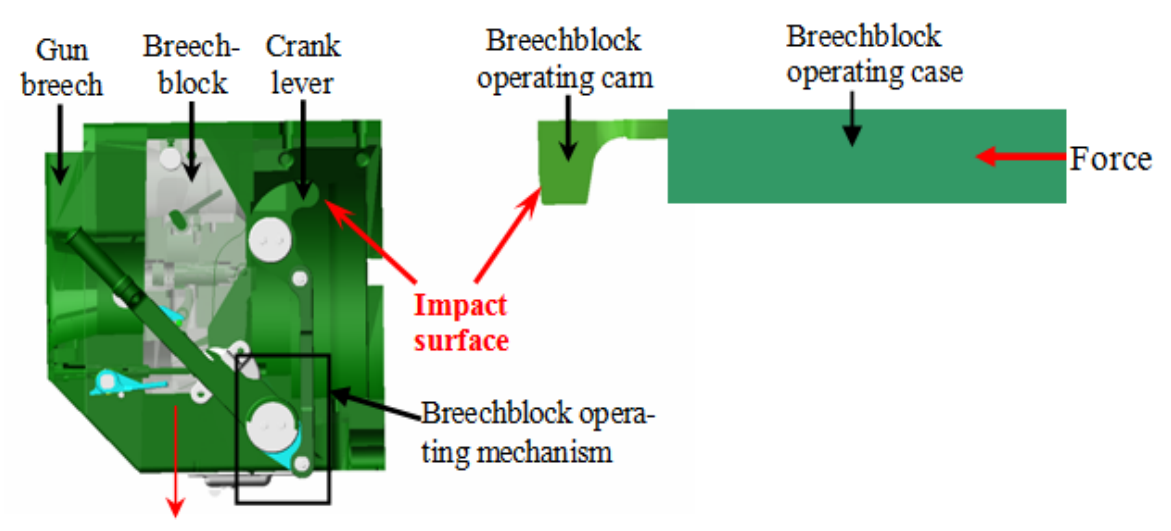

Fig. 3 Virtual prototype model of the shock test bed for breechblock system.

\section{Simulation tests}

The breechblock operating case is used to load with mass bodies in practice, so the breechblock operating mass could be changed through varying the numbers of mass bodies. For it is convenient to revise the parameters of the parts in MSC.ADAMS, there is no need to establish the model of mass body. As the whole breechblock operating mass was $50 \mathrm{~kg}$, the simulation experiments were performed based on the virtual prototype model when the breechblock operating force were $2000 \mathrm{~N}$, $2500 \mathrm{~N}, 3000 \mathrm{~N}, 3500 \mathrm{~N}$ and $4000 \mathrm{~N}$ separately. The simulation time is $0.9 \mathrm{~s}$ and the step is $0.001 \mathrm{~s}$. Under each condition, the breechblock can be opened by breechblock operating cam. Both the displacement of breechblock and rotation angle of crank lever were tested. The curves under the $2000 \mathrm{~N}$ are shown in Fig. 4.

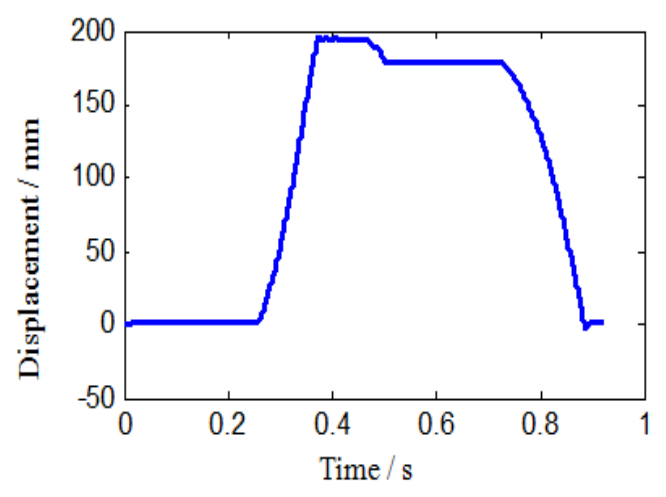

(a) Displacement of breechblock

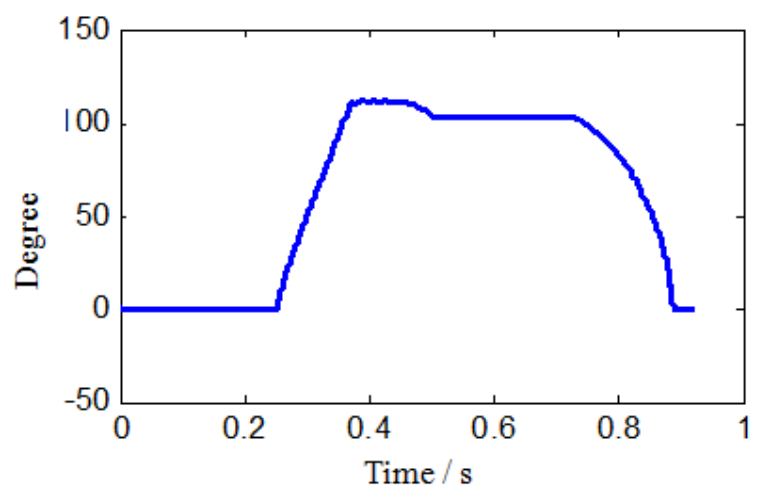

(b) Rotation angle of crank lever

Fig. 4 Dynamic characteristics of the shock test bed

The characteristic points of the curves are shown in Tab.1. They are the maximum displacement of breechblock and the maximum rotation angle of crank lever. In Tab.1, the theoretical value is the allowable range when the breechblock is opened. The numbers from 1 to 5 express the five conditions. 
Table 1: Comparison between simulation data and theoretical data

\begin{tabular}{|c|c|c|c|c|c|c|}
\hline \multirow[b]{2}{*}{ Parameters } & \multirow[b]{2}{*}{ Theoretical value } & \multicolumn{5}{|c|}{ Simulation value } \\
\hline & & 1 & 2 & 3 & 4 & 5 \\
\hline $\begin{array}{l}\text { The maximum displacement of } \\
\text { breechblock }(\mathrm{mm})\end{array}$ & 194.3 197.5 & 194.9 & 194.9 & 195.1 & 195.2 & 195.4 \\
\hline $\begin{array}{l}\text { The maximum rotation angle } \\
\text { of crank lever (Degree) }\end{array}$ & $111.4 \sim 112.4$ & 111.8 & 111.8 & 111.9 & 112.0 & 111.9 \\
\hline
\end{tabular}

\section{Conclusions}

In this paper, the virtual prototype model of shock test bed for breechblock system is established based on dynamic software MSC.ADAMS. The simulation experiments were performed based on the virtual prototype model when the breechblock operating force is $2000 \mathrm{~N}, 2500 \mathrm{~N}, 3000 \mathrm{~N}, 3500$ $\mathrm{N}$ and $4000 \mathrm{~N}$ separately. The dynamic characteristics curves of the parts are tested. The characteristic points of the curves under five simulation conditions are all in the theoretical range. In a word, the virtual prototype model of shock test bed can be used to analyze the dynamic characteristics of the parts before physical experiments.

\section{Acknowledgements}

The author wishes to thank the ISCI2015 for providing this template and all colleagues who previously provided technical support.

\section{References}

[1] Shi MY, Liu L and Chen YS. Research on process of opening block and ejecting container of a certain gun. Journal of Ballistics, Vol.15 (2003), p.23-28.

[2] Zhang J, Tang WX and Xu XX. Structural Optimization Design for Breechblock Extractor. Acta Armamentarii, Vol.33 (2012), p.647-651.

[3] Tang WX., Zhang J and Zhang P. Cartridge-case extracting analysis of some breech mechanism based on flexible body dynamics method. Applied Mechanics and Materials, Vol.43 (2011) 338-341.

[4] Zhang JZ, Cong MK, Zhang SX, et al. Research on failure analysis based on simulation about $125 \mathrm{~mm}$ tank gun breechblock extractor mechanism. Fire Control \& Command Control 2012, Vol.37 (2012), p.155-157.

[5] Zhu C and Zhao SY. Research on the extractor fatigue life of one self-propelled gun based on virtual prototype and FEM. Mechanism, Vol.40 (2013), p.22-24.

[6] Xie F and He H. Analysis on the static strength of the breechblock structure based on FEM. SCITECH Information Development \&Economy, Vol.17 (2007), p.182-183. 